\title{
The Finnish Family Competence Study: Knowledge of childbirth of nulliparous women seen at maternity health care clinics
}

\author{
PÄIVI RAUTAVA AND MATTI SILLANPÄÄ \\ From the Department of Public Health, University of Turku, Turku, Finland
}

\begin{abstract}
Study objective: To determine the level of knowledge about pregnancy and childbirth in nulliparous pregnant women.

Design: Survey using stratified randomised cluster sampling and confidential questionnaire analysis. Setting: Maternity health care clinics.

Participants: Of a total eligible population of 1713 nulliparous pregnant women from a Finnish province, 1443 took part. Of the remainder, 131 were not informed of the study and $139(8.8 \%)$ refused to participate. The distribution of occupation of the refusers was similar to the participants. Measurements and main results: Participants were questioned about their sociodemographic characteristics and about their knowledge of pregnancy and childbirth and psychomotor development in the infant, using 28 question sets (118 items). Results showed that, although social differences in the Finnish population are relatively small, there were still distinct differences in knowledge about childbearing in the different strata. The largest knowledge gaps were about health behaviour, particularly about alcohol intake and nutritional aspects of pregnancy and lactation, while knowledge of normal and abnormal delivery was relatively complete. When responses were divided into two groups with the median correct response rate as the cut off point, those with scores at or below the median were significantly more likely to have had modest education, to work in lower level employment, or to be very young or unemployed.

Conclusions: Differences still occur in knowledge levels among nulliparous pregnant women and particular guidance and care is needed for less advantaged mothers to ensure that they deliver healthy full term babies.
\end{abstract}

Primary prenatal care was organised rather systematically in Finland even before the second world war. In 1944, special legislation established it as a nationwide public health service provided free of charge. Antenatal examination before the 16th week of pregnancy was laid down as a prerequisite of eligibility for maternity benefits. In the course of the subsequent 20 years, the municipal maternity health care clinic system established its position and now enjoys the esteem and confidence of all social groups.

The follow up of the expectant mother is carried out at the maternity health care clinic, a unit of the local community health care system. These clinics are responsible for the care of the mother during pregnancy and in the 3 month period following childbirth, and for the care of the newborn baby for the first 2 weeks of life. At present, $99.9 \%$ of pregnant women use these services and $99.9 \%$ of babies are born in treatment units providing care at specialist level. The infant mortality rate in Finland- 5.8 per 1000 live born babies-is now the lowest in the world, and maternal deaths are practically non-existent. ${ }^{1}$

Mothers expect to receive individual high quality service and guidance about their own specific problems. $^{2-5}$ Often, however, it is difficult to determine a mother's support needs and level of knowledge. Therefore all mothers are given the same standard information by the maternity health care clinics. Some mothers, however, find the information too difficult to understand, while others find it simplistic. ${ }^{6-8}$ Knowledge is regarded as an important aspect of socialisation, and especially of primary socialisation, for the purposes of health education in 
an approach that sees health behaviour as an integral part of the individual's total behaviour. ${ }^{9}$

It is in the public interest for society to produce services which meet people's needs as adequately as possible. It has been assumed that individual health promotion and the high quality of medical care, on the one hand, and the provision of efficient health services at minimum cost on the other, are contradictory aims. Rightly directed, primary preventive care in the prenatal period will, however, produce remarkable savings in human suffering with relatively inexpensive measures. ${ }^{1011}$

The Finnish Family Competence Study was launched in January, 1985. Its main goal is to determine the way of life and health behaviour of young Finnish families in order to develop and improve the existing public health services in the fields of health education and socio-emotional support. It also aims to clarify the development of the child's health and way of life. This is a prospective follow up study and it will continue in each child until the end of the first school year. This paper presents the first part of the project which is restricted to the families of the nulliparous women and to the period of pregnancy.

The purpose of the present study was to determine (1) the level of knowledge in nulliparous women about pregnancy and delivery, health behaviour during pregnancy and lactation, and psychomotor development in the infant; and (2) the characteristics of mothers with a poor knowledge of childbirth.

\section{Methods}

\section{STUDY POPULATION}

The study was carried out in the Province of Turku and Pori, South-Western Finland (fig 1). At the end of 1985 the province had 713050 inhabitants. Women totalled $369228 ; 156376$ of them were $15-44$ years of age.

Target population-A study group of 1000 families was considered to have the proper size. Considering the proportion of nulliparous women in the total population, it was estimated that the target would be met within a year by including about one half of the population of the province in the study.

\section{STUDY DESIGN}

The method used in the study was one of stratified randomised cluster sampling. The study area was first divided into two parts: the northern area (Satakunta Central Hospital region) and the southern area (Turku University Hospital region). Each cluster consisted of a population living in a health authority area, the smallest unit of the national health care system, which is maintained by an urban municipality or, in most cases, by a league of smaller rural municipalities. As the degree of urbanisation is generally considered to

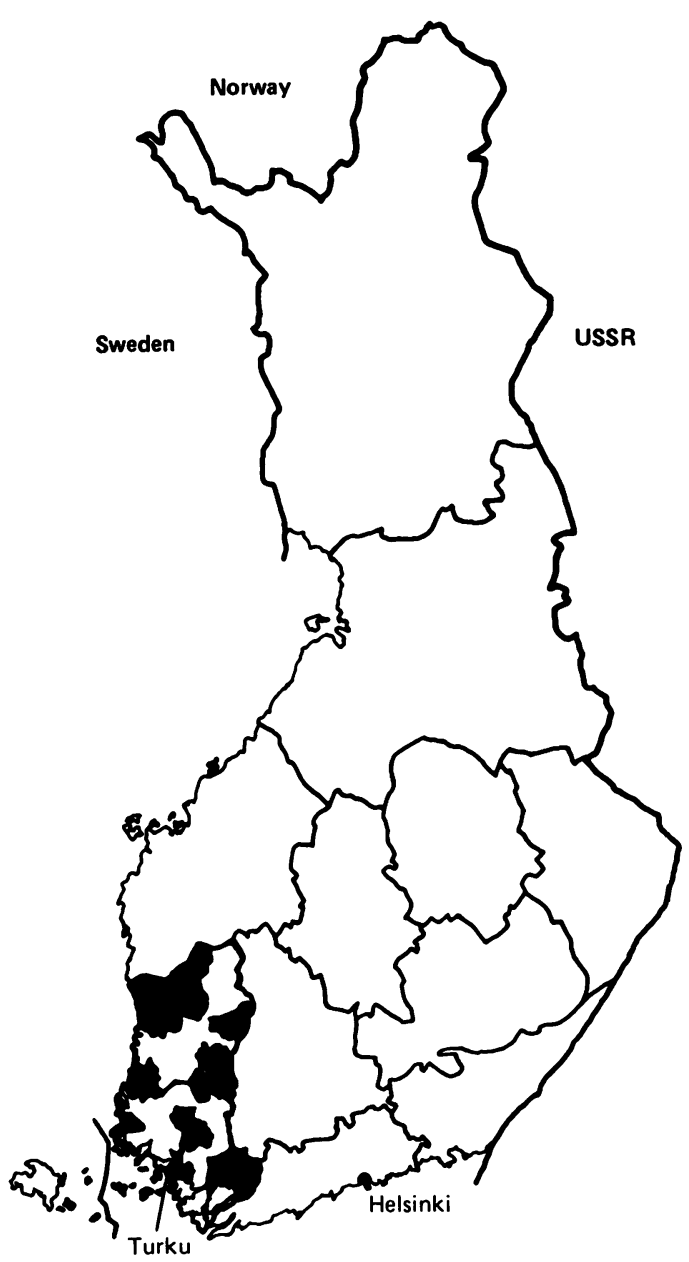

Fig 1 Map of Finland, showing the boundaries of the 11 provinces. The study municipalities in the Province of Turku and Pori, South-Western Finland, are shadowed

reflect the social and economic development of an area, ${ }^{12}$ a population weighted average of the degree of urbanisation of the individual municipalities was then defined, and the health authority areas were classified according to this averaged degree of urbanisation.

To obtain the desired proportion of one half of the total population of the province, 11 health authority areas were included in the study. The southern part of the province being more densely populated than the northern, six districts of the former area and five of the latter were included. The 11 health authority areas were randomly chosen, by drawing lots, according to the degree of urbanisation. The health authorities of Huittinen, Hämeenkyrö-Viljakkala, Kaarina-Piikkiö, Kankaanpää, Luoteis-Satakunta, Pöytyä, Rauma, 
Salo, Turku, Uusikaupunki and Vammala were thus chosen and were also willing to take part (fig 1). There were no significant differences in the mean degree of urbanisation between the municipalities of the health authorities chosen and all municipalities of the province $\left(\chi^{2} 12.992\right.$, df $\left.8, p=0 \cdot 112\right)$.

The study design was accepted by the Ethics Committee of the Turku University Faculty of Medicine.

The health authority areas included in the study had 67 maternity health care clinics. Special briefing meetings were held to give the staffs advance information about the study.

Data collection started in all study areas on January 1,1986 . The study group consisted of all nulliparous women in the areas who paid their first visit to the public health nurse at their maternity health care clinic on their own initiative during 1986. The subjects included married women, women living in a marriage like relationship and those living without a partner.

A total of 1713 women were eligible for the study. In 131 cases, however, potential subjects were not told about the study by nurses in the maternity health care clinics. Of the remaining 1582 mothers, $1443(91.2 \%)$ gave their informed consent and $139(8.8 \%)$ refused to participate. The occupational distribution of the 139 refusers was similar to that of the participants $\left(\chi^{2}=3.918\right.$, df $\left.3, p=0.2705\right)$. Other characteristics of the non-participants were not recorded. Of the 1443 participants, 32 had answered the questionnaire incompletely and were excluded from the study. The gross proportion of dropouts was $10.8 \%$ and net proportion $2 \cdot 2 \%$.

At the first visit to the maternity health care clinic (on the average in the tenth week of pregnancy), the mothers completed and returned the knowledge level questionnaire and were given another questionnaire, eliciting information on their sociodemographic background, to be completed at home. The latter questionnaire was to be returned in a closed envelope on their second visit to the clinic. The second questionnaire was returned by $1328(92 \%)$ of 1443 participants. The gross dropout rate for the second questionnaire was $16 \cdot 1 \%$ and the net rate $8.0 \%$.

The percentages in the Results section refer to those mothers who answered the particular questions, not necessarily to the total number of subjects.

The knowledge of pregnancy, delivery and psychomotor development of the infant was measured with 28 questions sets, consisting of a total of 118 items, in the following groups:

(1) Normal pregnancy and delivery (43 items)

(2) Abnormal pregnancy and delivery (16 items)

(3) Health behaviour during pregnancy and lactation (45 items)

(4) Psychomotor development of the infant (14 items).
The number of correct answers was counted for every question separately and summed up for each of the four main question categories. The question categories were compared by means of the Friedman two way analysis of variance and multiple comparisons tests. The mothers were then divided into two groups according to their level of knowledge, with the median as the cut off point. Thus the only criterion of placing the mothers in either of the groups was their knowledge level. Mothers whose knowledge level (according to the number of correct answers) was below the median or at the median were placed in the low knowledge group, and mothers whose knowledge level was over the median were placed in the high knowledge group.

Univariate associations with the categorised level of knowledge and demographic data were examined using Pearsons's $\chi^{2}$ test. Statistically significant variables were further examined by stepwise logistic regression analysis. The differences between the proportions of correct answers were tested with the $t$ test. The analyses were carried out by means of BMDP programs 2D, 3D, 4F, 3S and LR. ${ }^{13} 14$

\section{Results}

The mean age of the mothers was 25.4 (SD 4.3) years, range 16-42 years. There were 763 married mothers $(53.3 \%, n=1432)$ and $633(44 \cdot 2 \%)$ living in a marriage like relationship; the remaining $36(2.5 \%)$ were single and living alone or with their parents. In Finland primary school is completed at the age of 16 years. In the early 1970s the length of compulsory primary school education was increased from 6 to 9 years. Fourteen mothers $(1 \%, n=1333)$ had completed 6 years of primary school and one had not yet finished her 9 years of primary school. The other $1318(99 \%)$ had completed at least 9 years of primary school, and of them 558 mothers $(42 \%)$ had also finished secondary school (12 years of education).

A total of 190 mothers $(14.6 \%, n=1302)$ had no vocational training, and $84(6.5 \%)$ had not yet finished it; $526(40.4 \%)$ had completed a vocational training course or graduated from a vocational school, 367 $(28.2 \%)$ had received vocational education of college level and the remaining $135(10.4 \%)$ were university graduates.

There were 25 full time housewives $(2 \%, n=1267)$, 1036 mothers $(81.8 \%)$ were doing paid work, 74 $(5 \cdot 8 \%)$ were unemployed and $132(10 \cdot 4 \%)$ were studying.

The median of the correct answers was $70.3 \%$ for the total of 28 question sets measuring knowledge levels; $\mathbf{7 4 . 4 \%}$ for questions about normal pregnancy and delivery; $68.7 \%$ for those about abnormal pregnancy and delivery; $66.7 \%$ for those about health behaviour; 
and $71.4 \%$ for those about the psychomotor development of the infant. The mean of correct answers for all mothers was $70 \cdot 1 \%$.

Associations between knowledge levels and demographic variables showed that there were several characteristics differentiating between the low and high knowledge groups.

Normal pregnancy and delivery-The average proportion of correct answers for all mothers was $75 \cdot 1 \%$ (range $23-100 \%$ ). On the average, $86.9 \%$ of high knowledge mothers and $71.3 \%$ of low knowledge mothers knew the correct answers to more than half the question sets. The difference in the numbers of correct answers between knowledge groups was

Question sets

1. Duration of pregnancy ( 5 items)

2. Which parent's genes determine the child's sex ( 2 items)

3. Knowledge of conception (4 items)

4. Knowledge of pregnancy signs ( 6 items)

5. Estimation of gestational age of the fetus from the pictures ( 3 items)

6. Age at which movements of the fetus can be felt ( 3 items)

7. Function of the placenta (5 items)

8. Relief of labour pains ( 8 items)

9. Which part of the baby is presented first during delivery ( 4 items)

10. Delivery of the placenta ( 3 items)

Average

Fig 2 Knowledge of normal pregnancy and delivery

Question sets

11. Knowledge of toxaemia symptoms (7 items)

12. Knowledge of the correct way to act if the mother observes toxaemia symptoms ( 3 items)

13. Events considered as abnormal delivery (6 items)

Average significant $(\mathrm{p}<0.0001)$. Figure 2 shows the level of knowledge of the two groups for each question. Duration of pregnancy, sex determination, age at which movements of the fetus can be felt, and labour pain relief were more inadequately known by the low knowledge group. The estimation of the gestational age of the fetus from pictures was difficult for most mothers. Conception, signs of pregnancy, the first presenting part during delivery and delivery of the placenta were familiar to most mothers.

Abnormal pregnancy and delivery-The mean proportion of correct answers in all mothers was $68.4 \%$ (range $6-100 \%$ ). On average, $87.8 \%$ of high knowledge mothers and $68.1 \%$ of low knowledge

Proportions of mothers with more than half of cach question set correctly answered
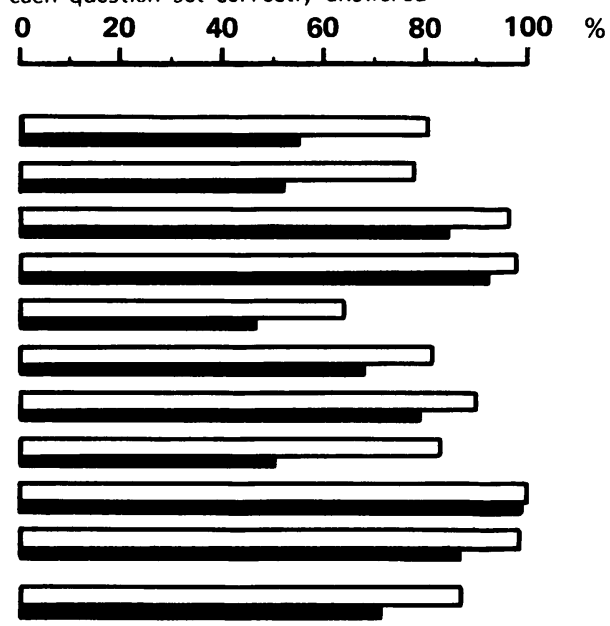

High knowledge group

Low knowledge group

Proportions of mothers with more than half of each question set correctly answered
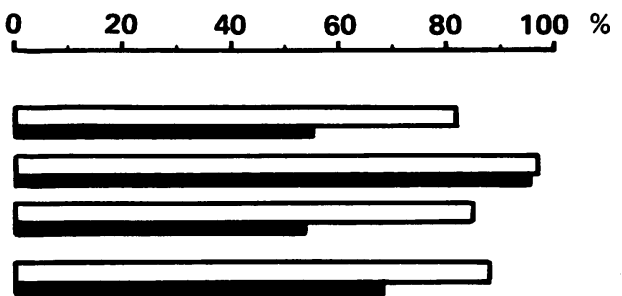

High knowledge group

Low knowledge group

Fig 3 Knowledge of abnormal pregnancy and delivery 
mothers knew the correct answers to more than half the questions. The difference was significant ( $p<0.0001$ ) (fig 3). Low knowledge mothers had defective knowledge of toxaemia symptoms and events considered as abnormal delivery (caesarean section, forceps delivery, suction cup delivery, twin delivery etc). Most mothers thought that a mother should contact the maternity health care clinic if she recognised any toxaemia symptoms.

Health behaviour during pregnancy and lactationThe mean proportion of correct answers for all mothers was $66.7 \%$ (range $18-98 \%$ ). The proportion of mothers who answered more than half the questions correctly was $68.0 \%$ for the high knowledge group and
$46.8 \%$ for the low knowledge group. The difference is significant $(p<0.0001)$ (fig 4$)$. This was the most difficult question category of the questionnaire for all mothers. The influence of alcohol and salt intake, nutrition during pregnancy and breast feeding, calcium requirements, substances passing across the placenta and substances entering the mother's milk, and all questions on allergy were difficult for low knowledge mothers. The influence of smoking during pregnancy, however, was familiar to most mothers.

Psychomotor development of the infant-The mean proportion of correct answers in all mothers was $67.8 \%$ (range $0-100 \%$ ). The proportion of mothers who correctly answered more than half the questions

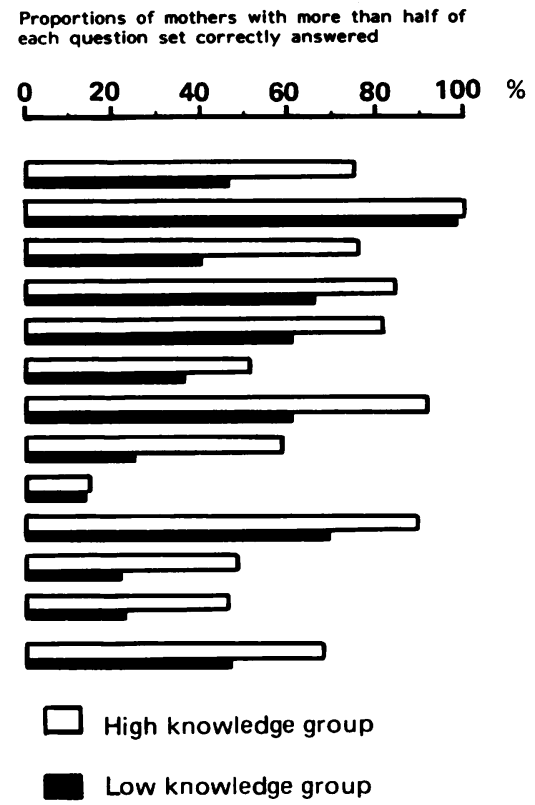

Fig 4 Knowledge of health behaviour during pregnancy and breast feeding

Proportions of mothers with more than half of each question set correctly answered

Question sets

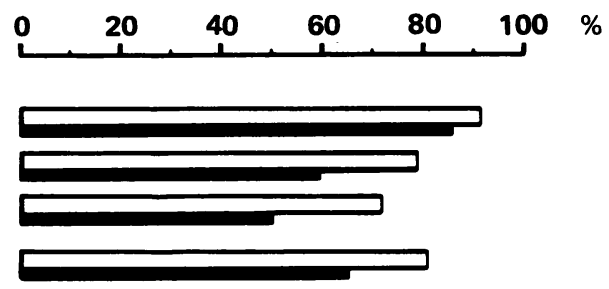

High knowledge group

Low knowledge group

Fig 5 Knowledge of child development 
in this question category was $80.6 \%$ and $64.9 \%$ for the two groups, the difference being significant $(p<0.0001)$ (fig 5). The question on nutrition of the newborn baby was familiar to mothers, whereas the performance of the newborn and development of the infant were inadequately answered by low knowledge group mothers.

\section{COMPARISON OF THE QUESTION CATEGORIES}

A statistically significant difference was found between the question categories in the Friedman two way analysis of variance $(p<0.0001)$ and multiple comparisons tests $(p<0.05)$. The mothers had a better knowledge $(p<0.05)$ of normal than of abnormal pregnancy and delivery. In the latter question category, the knowledge level was again better $(p<0.05)$ than in questions on health behaviour and the psychomotor development of the infant. The difference in the level of knowledge between the latter two question categories was not significant.

CHARACTERISATION OF THE LOW KNOWLEDGE GROUP Low knowledge mothers were characterised by a lower level of basic education and by employment in lower level occupations in the manufacturing industry and services. They were more frequently under 25 years of age (especially less than 20 years) and unemployed than high knowledge mothers. The table shows the explanatory power of each risk factor.

\section{Discussion}

The study sample is highly representative of the target population and shows no significant skewness in distribution. The sample was a stratified randomised cluster sample of pregnant women. Only nulliparous women were included in an effort to avoid the problem of differential experience. The study reached $92.4 \%$ of all possible cases. Of the 131 mothers to whom nurses did not offer participation in the study, $59(45 \%)$ were clients of one maternity health care centre with a staff who experienced the study as particularly burdensome. In general, Finnish mothers are rather easily motivated to participate in obstetric and paediatric studies.

The first questionnaire was completed during the first visit to the health care centre, to provide a preliminary view of the respondent's level of knowledge. The questionnaire was put in a closed 6 envelope and sent to the researchers. The knowledge्d

Table Demographic factors pertinent to the mothers' knowledge of childbearing

\begin{tabular}{|c|c|c|c|c|c|}
\hline Demographic factor & $\begin{array}{l}\chi^{2} \text { test in } \\
\text { univariate analysis } \\
p\end{array}$ & $\begin{array}{l}\text { Stepwise logistic } \\
\text { regression } \\
p\end{array}$ & $\chi^{2}$ & Odds ratio & $\begin{array}{l}95 \% \text { confidence } \\
\text { interval }\end{array}$ \\
\hline $\begin{array}{l}\text { Basic education } \\
12 \text { years } \\
9 \text { years } \\
6 \text { years }\end{array}$ & $<0.0001$ & $<0.0001$ & $137 \cdot 8$ & $\begin{array}{l}1.0 \\
2 \cdot 4 \\
4 \cdot 1\end{array}$ & $\begin{array}{l}1 \cdot 8-3 \cdot 2 \\
2 \cdot 7-6 \cdot 3\end{array}$ \\
\hline $\begin{array}{l}\text { Age } \\
\qquad 25 \text { years } \\
20-24 \text { years } \\
<20 \text { years }\end{array}$ & $<0.0001$ & $<0.0001$ & $45 \cdot 2$ & $\begin{array}{l}1 \cdot 0 \\
2 \cdot 0 \\
4 \cdot 7\end{array}$ & $\begin{array}{l}1 \cdot 5-2 \cdot 7 \\
2 \cdot 4-9 \cdot 2\end{array}$ \\
\hline $\begin{array}{l}\text { Occupation } \\
\text { white collar } \\
\text { services sector or primary } \\
\text { production } \\
\text { manufacturing }\end{array}$ & $<0.0001$ & $<0.0001$ & 16.9 & $\begin{array}{l}1.0 \\
1.5 \\
2.6\end{array}$ & $\begin{array}{l}1 \cdot 1-2 \cdot 0 \\
1 \cdot 7-4 \cdot 1\end{array}$ \\
\hline $\begin{array}{l}\text { Employment situation } \\
\text { studying } \\
\text { job not equivalent to education } \\
\text { housewife or job equivalent to } \\
\text { education } \\
\text { unemployed }\end{array}$ & $<0.0001$ & 0.001 & & $\begin{array}{l}1 \cdot 0 \\
1 \cdot 8 \\
2 \cdot 3 \\
2 \cdot 9\end{array}$ & $\begin{array}{l}1 \cdot 0-3 \cdot 0 \\
1 \cdot 4-3 \cdot 7 \\
1 \cdot 4-6 \cdot 1\end{array}$ \\
\hline Vocational training & $<0.0001$ & NS & & & \\
\hline Social status & $<0.0001$ & NS & & & \\
\hline
\end{tabular}


level questionnaire was pretested with pregnant and non-pregnant nulliparous women. The women who completed the questionnaire and the nurses in the health care centre considered its contents relatively difficult but found its language comprehensible even to non-professionals. The questionnaire on sociodemographic characteristics was also returned in a closed envelope to make the answers unidentifiable to the nurse, which gave the respondent more confidence in the study. The use of closed envelopes also made the situation easier for the staff, whose ethical duty would have been to provide information if they had observed any lack of knowledge in the subjects. The problem of refraining from correcting responses or providing reassurance has previously been noted by Downs and Fernback ${ }^{15}$ and Bowen $e t$ $a l .{ }^{16}$

The present study shows that nulliparous pregnant Finnish women have a reasonably good knowledge of pregnancy and childbirth. The mean of correct answers was $70 \cdot 1 \%$. Mothers were more familiar with normal than abnormal pregnancy and delivery. Questions on health behaviour during pregnancy and lactation were the most difficult. This is noteworthy, because unfavourable health behaviour during pregnancy and lactation signifies a considerable risk for the baby. A clear lack of knowledge about this question category was shown by both the high and the low knowledge groups. It is here that health education work is required from the maternity health care system.

The greatest single knowledge deficits involved the effects of alcohol, salt intake and infectious diseases on pregnancy, the effect on the child of substances absorbed into the mother's milk and the role of allergy. Eiser and Eiser, ${ }^{17}$ in an interview study of 48 English primigravid women, also found that the knowledge of hazards to fetal development was inadequate. It is surprising that the methods of pain relief during labour are poorly known, although it is a common topic in the Finnish mass media. Insufficient knowledge about the development of the infant shows that it is important to retain the subject in the health education programmes of maternal and baby clinics.

Although we divided the mothers into two groups only, with the median of correct answers as the cut off point, significant differences occurred between the groups in relation to certain sociodemographic factors. The difference in knowledge levels between the social strata was distinct, although social class differences in Finland are now smaller than ever before.

The present study leads to the following conclusions: (1) differences still occur in knowledge levels among pregnant nulliparous mothers; (2) particular guidance and care are needed for socially less advantaged mothers, mothers with a low level of basic education, those working in industrial and service occupations, and for unemployed and young mothers, to help them to deliver a healthy, full term baby; and (3) special attention should be paid to health education during pregnancy. Certain knowledge gaps about health behaviour can be harmful to the child.

Kaj Koskela, MD, Head of Office, Health Education Department of the National Board of Health, and Jaakko Vuori, MD, Medical Superintendent of the Turku and Pori Provincial Government, helped us to launch this project. Several obstetricians and midwives gave their invaluable comments on the questionnaires and helped us to collect the data. Juhani Tuominen, Lic Soc Sc, Lecturer in Biostatistics, Turku University Faculty of Medicine, and Olli Kaleva, MSc, carried out the statistical analyses. Mr Simo Merne MA, Turku University School of Translation Studies revised the English of the manuscript, and Miss Eija Suopajärvi helped in assembling the data. We wish to thank all of them for their invaluable contribution and assistance.

The study was financed by the National Board of Health of Finland.

Address for correspondence and reprints: Dr Päivi Rautava, Department of Public Health, Lemminkäisenkatu 1, 20520 Turku, Finland

\section{References}

${ }^{1}$ Official Statistics of Finland XI:78: Health services 1982. Yearbook of National Board of Health 1981-1982. Helsinki, 1984.

2 Riley EM. What do women want? The question of choice in the conduct of labour. In: Chard T, Richards $M$, eds. Benefits and hazards of the new obstetrics. (Clinics in Developmental Medicine. No. 64.) London: Heinemann, 1977: 62-71.

${ }^{3} \mathrm{O}$ 'Brien M, Smith C. Women's views and experiences of antenatal care. The Practitioner 1981; 225: 123-5.

${ }^{4} \mathrm{Garcia} J$. Women's views of antenatal care. In: Enkin M, Chalmers I, eds. Effectiveness and satisfaction in antenatal care. London: Heinemann, 1982: 81-91.

${ }^{5}$ Reid ME, McIlwaine GM. Consumer opinion of a hospital antenatal clinic. Soc Sci Med 1980; 14: 363-8.

${ }^{6}$ Kitzinger S. The good birth guide. London: Fontana, 1979.

${ }^{7}$ Macintyre S. The management of childbirth: A review of sociological research issues. Soc Sci Med 1977; 11: 477-84.

${ }^{8}$ Oakley A. The origins and development of antenatal care. In: Enkin M. Chalmers I, eds. Effectiveness and satisfaction in antenatal care. London: Heinemann, 1982: $1-21$.

${ }^{9}$ Baric L. Measuring family competence in the health maintenance and health education of children. Towards the aim of "Health for all by the year 2000". A project document. Manchester: WHO, 1982: 1-208. 
${ }^{10}$ Institute of Medicine. Preventing low birth weight. Washington, DC: National Academy Press, 1985; 212-37.

${ }^{11}$ Leveno KJ, Cunningham FG, Roark ML, Nelson SD, Williams ML. Prenatal care and the low birth weight infant. Obstet Gynecol 1985; 66: 599-605.

12 Statistical Yearbook of Finland. Volume 82. Helsinki: Central Statistical Office of Finland, 1987.

${ }^{13}$ Dixon WJ, ed. BMDP statistical software. Berkeley: University of California Press, 1983.

${ }^{14}$ Keinbaum DG, Kupper LL, Morgenstern H. Epidemiologic research. Belmont: Lifetime Learning Publication, 1982.
${ }^{15}$ Downs FS, Fernbach V. Experimental evaluation of a prenatal leaflet series in two project centers in New York City. Nursing Res 1973; 22: 498-506.

${ }^{16}$ Bowen RG, Rich R, Schlotfeldt RM. Effects of organized instruction for patients with the diagnosis of diabetes mellitus. Nursing Res 1961; 10: 151-9.

${ }^{17}$ Eiser C, Eiser JR. Health education needs of primigravidae. Child Care Health Dev 1985; 11: 53-60.

Accepted for publication March 1989 